\title{
FILOSOFÍA, ENSEÑANZA Y SOCIEDAD DE CONTROL
}

\author{
Silvio Gallo* \\ Universidad Estadual de Campinas, Brasil.
}

\section{Resumen}

El artículo problematiza en un primer momento, los desplazamientos y regulaciones de las denominadas por Deleuze "sociedades de control" a diferencia de las sociedades disciplinarias. Desde este marco general, en un segundo momento, aborda la discusión entre algunos mecanismos de control, como la evaluación y el método en la educación, y se cuestiona sobre ¿cuáles son los impactos en las escuelas y en los maestros, marcados por la disciplinarización y el control?; ¿qué líneas de fuga a esos mecanismos se pueden poner en marcha? Finalmente, en un tercer momento, analiza las condiciones para la enseñanza de la filosofía en las sociedades de control y muestra la potencia de apostarle a la constitución de pensamiento creativo propio, instigado por la experiencia del problema desde una pedagogía del concepto.

Palabras clave: Enseñanza de la filosofía, sociedades de control, pedagogía del concepto, resistencia educativa.

\begin{abstract}
Philosophy, Teaching and Control Societies.

Firstly, this article examines the displacements and regulations of Deleuze's "control societies", in contrast to disciplinary societies. Secondly, we begin the discussion about some control methods such as evaluation and method in education, and we pose the question: what are the impacts on schools and teachers, marked by disciplinarization and control?, and what lines of flight can be put into action with respect to these mechanisms?. Finally, we analyze conditions for the teaching of philosophy in control societies, and we place our stakes on the construction personal creative thought, instigated by the experience of the problem from a pedagogy of concept.
\end{abstract}

Key words: philosophy teaching, control societies, pedagogy of concept, educational resistance.

\section{INTRODUCCIÓN}

\footnotetext{
* Profesor de la Facultad de Educación de la Universidad Estadual de Campinas (UNICAMP) e Investigador del CNPq. Coordinador del $\mathrm{D} i \mathrm{~S}$-Grupo de Estudios e Investigaciones Diferencias y Subjetividades en Educación- FE-Unicamp.
} 
En un pequeño texto publicado en 1990, Gilles Deleuze afirmó que estaríamos dejando atrás las sociedades que Foucault caracterizó como disciplinares, y estaríamos entrando, rápidamente, en una nueva forma de sociedad, que él denominó sociedad de control. Podemos inferir que Deleuze tomaba los análisis hechos por Foucault de un tipo de poder posterior al disciplinar, el biopoder, dirigido no ya a los individuos, sino a los grandes conjuntos poblacionales. Si el ejercicio del poder disciplinar sobre los individuos exigía su confinamiento en instituciones (los lugares de producción de la disciplina), el ejercicio del biopoder ya no prevé tal confinamiento, una vez que se dirige a toda una población. Tal vez sea de esta "apertura" de la que habla Deleuze al señalar las sociedades de control.

Foucault no llegó a hablar de sociedades posdisciplinares ${ }^{1}$ y el mismo Deleuze escribió apenas este pequeño texto, en el cual coloca algunas pistas, además de referencias hechas de paso en una conferencia y en una entrevista ${ }^{2}$. El tema, por lo tanto, está abierto y carece de desarrollo y profundización. Pretendemos pensar los mecanismos y buscar las referencias básicas de estas sociedades que Deleuze llamó de control, para al final, tejer algunas consideraciones sobre la filosofía en éstas condiciones.

\section{Deleuze y las sociedades de control}

Intentemos, entonces, evidenciar cómo la cuestión de las sociedades de control fue abordada por Deleuze y por algunos autores que siguieron sus pistas. Una de las primeras veces -si no la primera- en que Deleuze habla de la sociedad de control es en la conferencia sobre el hecho de creación, pronunciada en la FEMIS el 17 de marzo de 1987; pero hay una referencia interesante en la célebre entrevista de él con Foucault, realizada en 1972, y que fue publicada bajo el título Os Intelectuais e o poder. Los dos están tratando de las instituciones disciplinares -instituciones de confinamiento, de secuestro, según Foucault-, comparando las prisiones con las fábricas y las escuelas:

No son apenas los prisioneros que son tratados como niños, sino los niños como prisioneros. Los niños sufren una infantilización que no es de ellos. En este sentido, es verdad que las escuelas se parecen un poco con las cárceles, las fábricas se parecen mucho con las cárceles. Basta ver la entrada de la Renault. $\mathrm{O}$ en otro lugar: tres permisos por día para hacer pipi ${ }^{3}$.

Se evidencia, así, que ya en las instituciones disciplinares se procedía a un ontrol dirigido hacia el cuerpo de cada individuo. Para atender al control que viene de arriba -usted no

\footnotetext{
${ }^{1}$ Michael Hardt corrobora esta afirmación: "De hecho, al anunciar tal paso, Deleuze formula, después de la muerte de Foucault, una idea que no encontró expresamente formulada en la obra de Foucault" (2000, p. $357)$.

${ }^{2}$ La conferencia “¿Qu'est-ce que l'act de création?” fue proferida en 1987 y publicada en el 2003 en Deux Régimes de Fous - textes et entrétiens, 1975-1995; el artículo "Post-Scriptum sobre las sociedades de control" fue publicado en L'Autre Journal, n. ${ }^{\circ}$ 1, mayo de 1990, y reeditada en Pourparlers, en el mismo año; una entrevista concedía a Toni Negri fue publicada en Futur Antérieur, n. ${ }^{\circ}$ 1, primavera de 1990, con el título Control y Devir, y también fue incluida en Pourparlers.

${ }^{3}$ DELEUZE G. Foucault. 1984, p. 73. (Agradezco a Marlene Torrezan la llamada de atención para esta cita).
} 
puede ir al baño cuando la fisiología indica, sino cuando el estándar determina que es un buen momento- el individuo necesita educar, disciplinar el cuerpo. El corte puesto por la sociedad de control es justamente que el individuo ya no necesita ser confinado en una institución para ser controlado. Puesto que la disciplina cumplió su papel histórico y ya está introyectada en el cuerpo de cada uno, se trata ahora de dirigirse al "cuerpo social", al colectivo. Se trata de llevar los mecanismos de control no sólo para los momentos de confinamiento, sino para todos los momentos. Control permanente. Y de ahí su formulación de que transitaríamos de las sociedades en que la disciplina es hegemónica a sociedades en que el control es hegemónico.

Acompañemos, entonces, aquella que debe ser la primera formulación de Deleuze sobre las sociedades de control, en la conferencia que hizo en marzo de 1987:

Es verdad que entramos en una sociedad que podemos llamar de una sociedad de control. Un pensador como Michel Foucault analizó dos tipos de sociedades bien próximos de nosotros. Aquellas que él denominó como sociedades de soberanía y aquellas otras que él denominó como sociedades disciplinares. El paso típico de una sociedad de soberanía a una sociedad disciplinar él lo hizo coincidir con Napoleón. La sociedad disciplinar se define -los análisis de Foucault se tornaron, con justicia, célebres- por la constitución de medios de secuestro: cárceles, escuelas, talleres, hospitales. La sociedad disciplinar tiene necesidad de estas instituciones. Este análisis engendró ambigüedades en ciertos lectores de Foucault, pues creyeron que este era su último pensamiento. Evidentemente, no. Foucault jamás creyó y dijo muy claramente que tales sociedades disciplinares no eran eternas. Más que ésto, él pensaba evidentemente que nosotros entraríamos en un nuevo tipo de sociedad. Ciertamente, conviviremos aún con toda la suerte de "restos" de las sociedades disciplinares por años y años, pero sabemos ya que estamos en sociedades de un otro tipo que debemos llamar, según la palabra propuesta por Burroughs -y Foucault nutría por él una viva admiración- de sociedades de control. Nosotros entramos en sociedades de control que se definen de un modo muy diferente de las sociedades de disciplina. Aquellos que velan por nuestro bien no tuvieron, o no tendrán más, necesidad de los medios de secuestro. Ahora todos ellos, las cárceles, las escuelas, los hospitales, son lugares de discusión permanente. ¿No será mejor distribuir los cuidados a domicilio? Sí, sin duda este es el futuro. Los talleres, las fábricas, están rompiéndose por todos los lados. ¿No serán mejores los regímenes de tercerización y el trabajo a domicilio? ¿No habrá otros medios de punir a las personas que no sea la cárcel? Las sociedades de control no pasarán más por los medios de secuestro. Aun la escuela. Es necesario vigilar bien los temas que nacen, que se desarrollarán a lo largo de cuarenta o cincuenta años y que nos explican que lo sensacional será hacer, al mismo tiempo, la escuela y la profesión. Será interesante saber cual será la identidad de la escuela y de la profesión a través de la formación permanente, que es nuestro futuro y que no más implicará forzosamente el reagrupamiento de los escolares en un medio de secuestro. Un control no es una disciplina. Con una carretera, no se encarcelan las personas, pero al hacer carreteras se multiplican los medios de control. No digo que esta sea la única finalidad de la carretera, pero las 
personas pueden rodar infinitamente y "libremente" sin estar confinadas y al mismo tiempo estando perfectamente controladas. Este será nuestro futuro ${ }^{4}$.

Esta primera formulación del tema recibiría un tratamiento un poco más extensivo y profundado en un artículo tan pequeño cuanto brillante y provocador, publicado en $1990^{5}$. En él, Gilles Deleuze afirma que estamos transitando de las sociedades disciplinares analizadas por Foucault -que dieron origen a la cárcel y a la escuela como conocemos hoy- hacia las sociedades de control, que ciertamente engendrarán nuevas instituciones, así como provocarán agudas transformaciones en las que conocemos.

El propio Foucault ya había puesto la cuestión en sus cursos en el Collège de Francia a mediados de los años setenta, sobre todo en aquel de 1975-1976, titulado É Preciso Defender a Sociedade ${ }^{6}$, y en los tres siguientes, en los cuales el filósofo explora la emergencia de un nuevo tipo de poder social, un poder sobre la vida, sobre la población, al cual él le dio el nombre de biopoder. Diferente del poder disciplinar, que constituyó instituciones para actuar sobre los individuos, en especial sobre los cuerpos de los individuos, esa nueva modalidad de poder extiende sus tentáculos sobre las poblaciones, sobre los grandes grupos sociales. Pero Foucault no llegó a examinar más detenidamente las características de las sociedades contemporáneas, donde este tipo de poder tiende a ser hegemónico, así como hizo con las sociedades disciplinares. Deleuze entra en la esfera de Foucault, en el pequeño artículo publicado en L'Autre Journal, para hablar de sociedades de control y esbozar sus principios generales. Sin embargo, tampoco Deleuze llevaría sus análisis adelante; quedaron apenas las interesantes pistas. Más recientemente, un análisis de la geopolítica contemporánea, tomando como instrumentos los conceptos de biopoder y de sociedad de control, fue emprendido por Antonio Negri y Michael Hart, en la obra Imperio, llevando adelante las ideas dejadas por Foucault y por Deleuze ${ }^{7}$.

Partamos entonces del artículo de Deleuze para verificar sus implicaciones para la educación. Sigamos su raciocinio:

Foucault situó las sociedades disciplinares en los siglos XVIII y XIX; alcanzan su apogeo en el inicio del siglo XX. Ellas proceden a la organización de los grandes medios de confinamiento. El individuo no cesa de pasar de un espacio cerrado a otro, cada uno con sus leyes: primero la familia, después la escuela ('usted no está más en su familia'), después el cuartel ('usted no está más en la escuela'), después la fábrica, de vez en cuando el hospital, eventualmente la cárcel, que es el medio de confinamiento por excelencia [...]. Pero lo que Foucault también sabía era la brevedad de este modelo: para él substituían las sociedades de soberanía cuyo

\footnotetext{
${ }^{4}$ DELEUZE. G. Deux régimes de fous (Textes et entretiens, 1975-1995). Paris: Les Éditions de Minuit, 2003, pp. 299-300).

${ }^{5}$ DELEUZE. G. "Post Scriptum sobre las sociedades de control". En: Conversaciones, Rio de Janeiro, Editora 34, 1992.

${ }^{6}$ Los cursos en que Foucault analizó el biopoder son: É preciso defender a sociedade (Es necesario defender la sociedad) (1975-1976); Segurança, território e população (Seguridad, territorio y población) (1977-1978); Nascimento da biopolítica (Nacimiento de la biopolítica) (1978-1979); y Do governo dos vivos (De los gobiernos de los vivos) (1979-1980).

${ }^{7}$ NEGRI Antonio y HARDT. Michael Imperio (Imperio). Rio de Janeiro, Ed. Record, 2001.
} 
objetivo y funciones eran completamente diferentes (acaparar, más que organizar la producción, decidir sobre la muerte, más que dirigir la vida); la transición fue hecha progresivamente, y Napoleón parece haber operado la gran conversión de una sociedad a otra. Pero las disciplinas también conocerían una crisis, en favor de las nuevas fuerzas que se instalaban lentamente y que se precipitarían después de la Segunda Guerra Mundial: sociedades disciplinares es el que ya no éramos más, lo que dejábamos de ser $^{8}$.

Después de esa delimitación histórica del problema, Deleuze nombra esas nuevas formaciones sociales que están, cada día más dirigiendo nuestras vidas, llamando la atención para el hecho de que, en la misma medida en que los instrumentos de dominación son otros, necesitamos también buscar, crear armas alternativas de liberación:

Son las sociedades de control las que están substituyendo las sociedades disciplinares. 'Control' es el nombre que Burroughs propone para designar el nuevo monstruo, y que Foucault reconoce como nuestro futuro próximo. Paul Virilio también analiza sin parar las formas ultra-rápidas de control del aire libre, que substituyen las antiguas disciplinas que operaban en la duración de un sistema cerrado. No cabe invocar producciones farmacéuticas extraordinarias, formaciones nucleares, manipulaciones genéticas, aun que ellas sean destinadas a intervenir en el nuevo proceso. No se debe preguntar cuál es el régimen más duro, o lo más tolerable, pues es en cada uno de ellos que se enfrentan las liberaciones y las sujeciones. Por ejemplo, en la crisis del hospital como medio de confinamiento, la sectorización, los hospitales-día, la atención a domicilio pudieron marcar de inicio nuevas libertades, pero también pasaron a integrar mecanismos de control que rivalizan con los más duros confinamientos. No cabe temer o esperar, pero buscar nuevas armas 9 .

Deleuze se pone entonces a examinar la lógica de funcionamiento de las sociedades de control, siempre las compara con las sociedades disciplinares, examinando qué desplazamientos ponen en flujo esas nuevas sociedades. Toma la metáfora del topo, creada por Marx en El dieciocho de brumario de Luis Bonaparte, para explicar la interrelación intrínseca entre las diferentes crisis económicas, para afirmar que, en el caso de las sociedades de control, la imagen de la serpiente, con sus varios segmentos y su cuerpo ondulante, siempre visible, viene siendo la más apropiada para las nuevas formaciones sociales. Muestra que, progresivamente, el eje económico se desplaza de la producción a la circulación, de la producción a los servicios. En palabras de Deleuze, la empresa (sistema abierto) sustituye la fábrica (sistema cerrado). En la misma medida, la escuela, institución disciplinar y, por lo tanto, sistema cerrado, de confinamiento, va siendo paulatinamente substituida por los emprendimientos de formación permanente, abiertos, que transcienden la escuela como instancia formadora, de la misma forma que el control continuo viene para sustituir el examen, ese ícono de las instituciones disciplinares.

\footnotetext{
${ }^{8}$ DELEUZE, G. Conversações (Conversaciones). Rio de Janeiro: Ed. 34, 1992, pp. 219-220.
}

${ }^{9}$ Ibídem, p. 220. 
El filósofo muestra que la característica básica de estas sociedades es dar la ilusión de una mayor autonomía, pero no por eso dejan de ser mucho más controladoras que las anteriores. Por ejemplo, hoy no necesito ir a la agencia bancaria, pues controlo mi cuenta corriente por teléfono, por fax o por el computador, vía Internet; parezco, por eso, tener una autonomía mucho mayor. ¡Sin embargo, la facilidad del acceso informatizado permite a los gobiernos -y aun a los propios bancos- que yo sea vigiado mucho más de cerca, y lo que es peor, en la mayoría de las veces, ¡sin ni siquiera sospecharlo! En la medida en que el control escapa de las instituciones y se hace fuera de ellas, se torna más tenue, más fluido y, por lo mismo, más poderoso, una vez que se infiltra mejor y más astutamente por todas las rendijas.

La tónica, en las sociedades de control, parece ser aún la de los procesos continuos; nunca termina, pero los flujos van sumándose unos a otros:

En las sociedades de disciplina no se paraba de recomenzar (de la escuela al cuartel, del cuartel a la fábrica), mientras que en las sociedades de control nunca se termina nada, la empresa, la formación, el servicio, siendo los estados meta estables y coexistentes de una misma modulación, como que un deformador universal. Kafka, que ya se instalaba en el cruzamiento de los dos tipos de sociedad, describió en El proceso las formas jurídicas más temibles: la remisión aparente de las sociedades disciplinares (entre dos confinamientos), la moratoria ilimitada de las sociedades de control (en variación continua) son dos modos de vida jurídicos muy diferentes, y si nuestro derecho, él mismo en crisis, vacila entre ambos, es porque salimos de uno para entrar en el otro ${ }^{10}$.

Esa continuidad de los flujos identifica las sociedades de control con un funcionamiento por modulación. Mientras que las sociedades disciplinares operaban por moldeados fijos -el molde disciplinar era aplicado a las más diversas instituciones-, las sociedades de control operan por una modulación permanente, regulando todo el conjunto social. Sobre esta característica de la modulación de las sociedades de control podemos buscar más elementos en otra obra de Deleuze, que no posee ninguna relación directa con esta. Sin embargo, como su comprensión de concepto es marcada por la heterogeneidad de componentes $^{11}$, pienso que sea posible la analogía. En Francis Bacon - Lógica de la Sensación, Deleuze afirmó que "la pintura es el arte analógico por excelencia"12 y que el lenguaje analógico funciona por modulación, mientras que el lenguaje digital funciona por integración. El punto que él destaca es que la modulación nos permite comprender el lenguaje, además de la similitud, y, por lo tanto, ver posibilidades en el arte además de la representación. Para lo que nos interesa en este momento, sin embargo, basta quedar con el ejemplo que él trae de los sintetizadores:

\footnotetext{
${ }^{10}$ Ibídem, pp. 221-222.

${ }^{11}$ Sobre la noción de concepto, ver Gilles Deleuze y Félix Guattari, ¿Quest-ce que la philosophie? Paris: Minuit, 1991 (edición brasilera: O que é a filosofia? (¿Qué es la filosofía?) Rio de Janeiro: Ed. 34, 1992).

12 DELEUZE, Gilles. Francis Bacon - Lógica da Sensação (Lógica de la Sensación). Rio de Janeiro: Jorge Zahar, 2007, p. 118.
} 
Los sintetizadores analógicos son "modulares": ellos ponen elementos heterogéneos en conexión inmediata, introducen entre esos elementos una posibilidad de conexión propiamente ilimitada, en un campo de presencia o sobre un plan finito en que todos los momentos son actuales y sensibles. Al paso que los sintetizadores digitales son "integrados": su operación pasa por una codificación, por una homogeneización y binarización de los datos, en un plan distinto, infinito de derecho, y de lo cual el sensible resultará por convención-traducción ${ }^{13}$.

Pienso que es posible, pues, decir que las sociedades disciplinares funcionaban digitalmente, por integración de los individuos al espacio homogéneo de las instituciones; las sociedades de control, por otro lado, funcionan analógicamente, por la modulación de los elementos heterogéneos, estableciendo las conexiones necesarias para la producción del control. Si las sociedades disciplinares necesitaban "secuestrar" los individuos, confinarlos en las instituciones, para moldearlos, para adecuarlos al molde institucional predefinido, en las sociedades de control este efecto es alcanzado por la modulación, atravesando las diferentes instancias y espacios sociales.

Esta modulación permite un alcance mayor que el confinamiento disciplinar, a pesar de que responda a los mismos objetivos, de acuerdo con lo que destacan Antonio Negri y Michael Hardt en Imperio:

La sociedad de control puede, de esa forma, ser caracterizada por una intensificación y una síntesis de los aparatos de normalización de disciplinaridad que animan internamente nuestras prácticas diarias y comunes, pero, en contraste con la disciplina, ese control se extiende bien para fuera los locales estructurados de instituciones sociales mediante redes flexibles y fluctuantes ${ }^{14}$.

La tesis de Negri y de Hardt es que la sociedad de control es la forma adoptada por el modelo político del imperio: "la forma social tomada por ese nuevo Imperio es la sociedad de control mundial" "15. Hardt muestra que los Aparatos Ideológicos de Estado, pensados por Althusser, permean las sociedades de control:

El control es, así, una intensificación y una generalización de la disciplina, en que las fronteras de las instituciones fueron superadas, tornadas permeables, de forma que no hay más distinción entre fuera y dentro. Se debería reconocer que los aparatos ideológicos de Estado también operan en la sociedad de control, y tal vez con más intensidad y flexibilidad de que Althusser jamás imaginó ${ }^{16}$.

\footnotetext{
${ }^{13}$ Ibídem, pp. 117-118).

14 Antonio Negri y Michael Hardt. Império (Imperio). Rio de Janeiro: Record, 2001, pp. 42-43. En:.

${ }^{15}$ NEGRI Antonio y HARDT. “A Sociedade Mundial de Controle” (La Sociedad Mundial de Control) En: ALLIEZ, E. (Comp.): Gilles Deleuze: una vida filosófica. São Paulo: Ed. 34, 2000, p. 358

16 Ibídem, pp. 369-370.
} 
Para finalizar esta exposición alrededor de la formulación de las sociedades de control a partir de las pistas dejadas por Deleuze, recurro a un artículo de Rogério da $\operatorname{Costa}^{17}$ que evidencia que los mecanismos de regulación de las sociedades de control están dirigidos más hacia los elementos inmateriales de la sociedad que a la materialidad de los cuerpos de los individuos, como en las sociedades disciplinares. Según este autor, las sociedades disciplinares producían un flujo vertical y jerárquico de las informaciones (integración digital), mientras que en las sociedades de control tenemos un flujo de orden rizomático, reticular, interconectando los diferentes puntos (modulación analógica). De esto resulta que:

Ninguna forma de poder parece tan sofisticada como aquella que regula los elementos inmateriales de una sociedad: información, conocimiento, comunicación. El estado que era como un gran parásito en las sociedades disciplinares, extrayendo más valía de las actividades de los individuos, hoy está tornándose una verdadera matriz omnipresente, modulando continuamente el flujo de esos mismos individuos, según variables cada vez más complejas. En la sociedad de control estaríamos pasando de las estrategias de interceptación de mensajes al rastreamiento de estándares de comportamiento... ${ }^{18}$.

En las sociedades de control, que cada vez más parecen materializarse frente a nuestros ojos, la tónica dominante es, por lo tanto, el control permanente sobre los flujos de información, sobre los estándares de comportamiento de los individuos, generando relaciones de poder más difusas y descentradas, pero aun por eso más abarcantes y más eficientes en los procesos de regulación social.

Frente a este cuadro, ¿cómo pensar la educación?, ¿cuáles son los impactos sufridos por las escuelas, instituciones marcadas en la modernidad por la disciplinarización?, ¿cómo ellas están transformándose frente a los mecanismos de control?

\section{Educación y control}

La educación siempre se ha valido de los mecanismos de control. Si existe una función manifiesta de la enseñanza -la formación/información del alumno, abrirle acceso al mundo de la cultura sistematizada y formal-, hay también funciones latentes, como la ideológica -la inserción del alumno en el mundo de la producción, adaptándose a su lugar en la máquina. La educación asume, de esta manera, su actividad de control social. Y tal control acontece en las acciones más insospechadas.

Foucault denunció los mecanismos más explícitos de la escuela, cuando trazó en Vigilar y Castigar los paralelos de esta institución social con la cárcel. Mostró que la estructura física y arquitectónica de la escuela está dirigida, así como en la cárcel, hacia la

${ }^{17}$ DA COSTA Rogério, Sociedade de Controle (Sociedad de Control), in: Jorge Cruz (org.). Gilles Deleuze - sentidos y expresiones. Rio de Janeiro: Ed. Ciencia Moderna, 2006, pp. 31-46.

18 DA COSTA Rogério. "Sociedade de Controle". En: Cruz, Jorge (Comp.): Gilles Deleuze - sentidos y expresiones. Rio de Janeiro: Ed. Ciência Moderna, 2006, p. 35. 
vigilancia/control de sus alumnos/prisioneros. Son muchos los ojos que sentimos sobre nosotros, lo que introyecta el control y hace que nosotros mismos nos vigilemos. Pero el filósofo francés también apuntó otros mecanismos de la escuela mucho menos explícitos, como la disciplinarización. Hay docenas de argumentos pedagógicos para explicar por qué razón el conocimiento está dividido en disciplinas: facilita el acceso/comprensión del alumno, etc., etc. Pero, por detrás de eso, acecha el control: compartimentalizando, fragmentando, es mucho más fácil de controlar el acceso, el dominio que los alumnos tendrán, y también controlar lo que ellos saben. Recordemos el sabio consejo del general romano: "Dividir para gobernar".

Otro aspecto de este término ambiguo, la disciplinarización, se refiere más directamente a la cuestión del poder. La escuela es el lugar de la disciplina, de su aprendizaje y de su ejercicio. No está lejos el tiempo en que los alumnos hacían en los patios de las escuelas públicas, antes de entrar al aula, ejercicios de orden cerrado, como reclutas en un cuartel, y seguramente en algunos lugares eso aún sea práctica común. La disposición de pupitres en un salón de clase, por otro lado, busca también la disciplinarización de los alumnos y una mejor posibilidad de control por el profesor, que domina geopolíticamente la clase, percibiendo su mapa geográfico y pudiendo armar una estrategia/táctica de clase. Aún en el caso de las pedagogías nuevas, que rompen con la tradicional fila de los pupitres, permanece una forma implícita similar a la del general que dispone su ejército en el campo de batalla, en este caso, el salón de clase. En otras palabras, el salón nunca es un caos, con los alumnos ocupando el espacio desordenadamente, hay siempre una organización implícita que busca posibilitar la acción pedagógica y que trae también consigo la marca del ejercicio del poder, que debe ser sufrido e introyectado por los alumnos.

Un tercer y último aspecto es lo que nos debe interesar más de cerca. Para disciplinarizar y controlar, la escuela hace uso del mecanismo de la evaluación, también recubierto de mil argumentos didáctico-pedagógicos, pero que es una marca indeleble del poder y del control. Pues, dirán algunos, ¿cómo educar si no tuviéramos un feedback de los alumnos, que sólo es posible a través de los más diversos mecanismos de evaluación, para reorganizar continuamente el proceso pedagógico? Y tendrán toda la razón. Pero, por otro lado, también no podemos dejar de reconocer que la única forma que la burocracia escolar encontró a lo largo de los siglos para materializar los resultados de tales evaluaciones fue su cuantificación en términos de notas y, más tarde, de conceptos que, en el fondo, nada cambian, pero continúan clasificando y cuantificando. Si dejamos de lado el carácter despreciable de esta cuantificación en nombre de su absoluta necesidad, no podemos negar que ella acaba sirviendo como instrumento de poder. El profesor es aquel que tiene el poder de dar la nota y, así, aprobar o reprobar al alumno.

Ya en el inicio de este siglo los pedagogos anarquistas rechazaban la realización de pruebas, exámenes y la atribución de notas a los alumnos, denunciando el carácter eminentemente político y dominador de estas acciones ${ }^{19}$. Es exactamente esta cuestión la

\footnotetext{
${ }^{19}$ Un buen ejemplo es el caso de Francesc Ferrer i Guàrdia, creador de la Escuela Moderna de Barcelona, en 1906, que influenció la creación de decenas de escuelas operarias en Brasil en las tres primeras décadas
} 
que está detrás de la resistencia de los profesores en aceptar abdicar de su poder de evaluar. Evaluar es decidir; decidir es dominar; dominar es tener poder. No tenemos un salario digno, perdemos nuestro estatus y lo que nos resta, y a lo que nos agarramos con firmeza, es nuestro poder de decidir sobre la vida de los alumnos y, así, dominarlos. No importa si mi salón es pesado, si el contenido que "enseño" no es ni un poco significativo. Como voy a dar una nota al alumno, aprobándolo o reprobándolo, él está obligado a asistir a la clase. Como si asistir a toda y cualquier clase fuese el criterio absoluto para una educación de calidad...

Pero me parece que es justamente ahí que nos engañamos; cuando pensamos que somos "señores de la escuela", que estamos siendo sujetos del proceso, estamos en verdad sujetados. Pienso que estamos absolutamente seguros del hecho de que algo que es enseñado es aprendido. Pero eso no necesariamente acontece. Inclusive la pedagogía acuñó la expresión "enseñanza-aprendizaje", buscando denotar la ruta de doble vía en la cual debe constituirse ese proceso, pero la expresión (como tantas otras) cayó en un modismo fácil, y pienso que ya no significa gran cosa.

Debemos desconfiar de la fácil certeza de que aquello que es enseñado es aprendido. $\mathrm{O}$ de que aquello que es transmitido es asimilado. Ya en los tiempos bíblicos se hablaba de que las semillas pueden o no germinar, dependiendo del suelo en que caen; pues bien: enseñar es como lanzar semillas, que no sabemos si germinarán o no, y aprender es incorporar la semilla, hacerla germinar, crecer y fructificar, produciendo lo nuevo.

De esto podemos concluir que no necesariamente lo que es enseñado es aprendido. El aprendizaje es un proceso sobre el cual no se puede ejercer absoluto control. Podemos planear, podemos ejecutar todo de acuerdo con lo planeado, tomando todos los cuidados imaginables, pero siempre algo podrá huir del control, escapar por entre los bordes, trayendo a la luz un resultado insospechado, inimaginable. Ahí se encuentra, en mi manera de ver, la belleza del proceso educativo: actuamos sin nunca saber cuál será el resultado de nuestras acciones. Una clase puede "funcionar" muy bien en nuestras cabezas, pero producir situaciones y resultados completamente distintos en los alumnos; o producir los resultados esperados, pero, quién sabe, meses o años después.

Lanzamos nuestras semillas sin saber si darán origen a flores o a monstruos, incluso, si darán origen a cosa alguna... Esa "dosis de incertidumbre" presente en el proceso educativo, que es la gran piedra en el camino de una pedagogía moderna que se quiso hacer ciencia, fue bien identificada por Deleuze, al final de los años sesenta, en la obra Diferencia y Repetición ${ }^{20}$. El filósofo mostró allí que hasta puede haber métodos para enseñar (ellos por lo menos sirven para tranquilizar las conciencias perturbadas de los profesores), pero no hay métodos para aprender. El método es una máquina de control, pero el aprendizaje está más allá de cualquier control; el aprendizaje escapa, siempre. El

del siglo. Para el lector interesado en conocer más sobre las experiencias anarquistas en educación sugiero la lectura de Sílvio Gallo, Pedagogia do Risco (Pedagogía del Riesgo). Campinas: Ed. Papirus, 1995.

${ }^{20}$ Ver en la edición brasilera más reciente de Diferença e Repetição (Diferencia y Repetición) (Editora Graal, 2006), principalmente las páginas 236 a 239, los tópicos finales del capítulo A Imagem do Pensamento (La Imagen del Pensamiento). 
aprendizaje no puede ser circunscrito a los límites de una clase, de la audición de una conferencia, de la lectura de un libro; él sobrepasa todas esas fronteras, rasga los mapas y puede instaurar múltiples posibilidades.

Pero con el surgimiento de las sociedades de control, la cuestión de los mecanismos de control en los procesos educativos gana nuevos contornos. Es claro que la escuela, en particular, y los procesos educacionales, en general, no quedan por fuera en esa nueva ola social. Después de analizar la producción histórica de las sociedades de control y su lógica interna de funcionamiento, Deleuze pasa a examinar cuál sería su programa, eso es, los indicios que vamos viviendo, experimentando, sufriendo de su consolidación. Apunta rápidamente algunas transformaciones por las cuales deben pasar y ya están pasando las principales instituciones disciplinares, como las cárceles, los hospitales, las empresas, las escuelas. Quedémonos aquí apenas con las transformaciones apuntadas para las instituciones escolares:

En el régimen de las escuelas: las formas de control continuo, evaluación continua, y la acción de la formación permanente sobre la escuela, el abandono correspondiente de cualquier investigación en la Universidad, la introducción de la 'empresa' en todos los niveles de la escolaridad ${ }^{21}$.

Y, en una entrevista concedida a Antonio Negri para la revista Futur Antérieur, en la misma época de la publicación del artículo ya citado, Deleuze explicitaría también la tecnificación de la escuela en las sociedades de control, con una relación cada vez mayor con las empresas:

Que está siendo implantado, a las ciegas, son nuevos tipos de sanciones, de educación, de tratamiento. Los hospitales abiertos, la atención a domicilio, etc., ya surgieron hace mucho tiempo. Se puede prever que la educación será cada vez menos un medio cerrado, distinto del medio profesional -otro medio cerrado-, pero que los dos desaparecerán en favor de una terrible formación permanente, de un control continuo ejerciéndose sobre el operario/alumno o el ejecutivo/universitario. Intentan hacernos creer en una reforma de la escuela, cuando se trata de una liquidación ${ }^{22}$.

¿Notaron algo similar a los procesos que hemos asistido en la educación brasilera y latinoamericana, sobre todo en los últimos quince o veinte años? No, no es mera coincidencia. Las reformas propuestas y llevadas a cabo por los gobiernos no son movidas apenas por un deseo y una necesidad de una educación de calidad; o, dicho de otra manera, el paradigma de calidad asumido por ellos es el de la calidad total, este tótem del neoliberalismo que insiste en instaurar un nuevo orden mundial, bajo su absoluto y transparente control. Es así como se propone la evaluación continua, la formación permanente, la sociedad con las empresas y estos mecanismos para mejorar la calificación del operario brasilero y latinoamericano, la disminución de los índices de

${ }^{21}$ DELEUZE. G Conversações, Op. cit, 1992, p. 225.

${ }^{22}$ Ibídem, p. 216. 
reprobación y evasión escolar. ¡Es necesario que se muestre al mundo que Brasil es un país capacitado, apto para andar de manos dadas con la modernidad! Aunque la modernidad signifique más control, y un servilismo aún mayor...

Sí, este discurso necesita ser denunciado y criticado. ¡Pero simplemente no podemos hacerlo con las armas viejas! ¡No podemos apuntar una daga para combatir un misil con ojiva nuclear! Si quisiéramos hacer una oposición seria y consecuente al discurso oficial, continuando en la lucha por un sistema de enseñanza serio, competente y verdaderamente de calidad, debemos buscar una nueva táctica, que implica también que asumamos nuestros errores.

En la entrevista a Antonio Negri en 1990, Deleuze afirmó que:

Creer en el mundo es lo que más nos falta; nosotros perdemos completamente el mundo, nos despojaron de él. Creer en el mundo significa principalmente suscitar acontecimientos, aunque sean pequeños, que escapen al control, o engendrar nuevos espacio/tiempos, aun de superficie o volumen reducidos [...]. Es al nivel de cada intento que se evalúan la capacidad de resistencia o, al contrario, la sumisión a un control ${ }^{23}$.

¿Qué podemos hacer nosotros, educadores, para creer en el mundo? ¿Qué acontecimientos podemos suscitar? ¿Qué líneas de fuga a los mecanismos de control podemos poner en marcha?

Debemos, pienso, comenzar por abdicar al discurso del poder. No podemos defender la rigidez del sistema de notas/evaluación que culmina en la reprobación, pues subyace a él nuestro sádico deseo de poder despótico, que es el mismo que mueve las acciones oficiales. Si la tónica del momento es la evaluación continua, el acompañamiento del alumno, sin su reprobación, por entre los cursos (la progresión continua), podemos hacer de esa acción pedagógica una acción verdaderamente educativa, contribuyendo de hecho para la formación de los seres humanos que se encuentran cotidianamente con nosotros en nuestros salones de clase. Pero simplemente no podemos actuar de la misma forma como actuábamos anteriormente: es obvio que así las cosas no van a funcionar. Negar el pasado no es la mejor forma de encarar el futuro, pero agarrarse a él tampoco posibilita un presente satisfactorio. Las mayores batallas fueron vencidas por los ejércitos que supieron aprovecharse de las armas del enemigo, volviéndolas contra él mismo. Pienso que ese debe ser nuestro camino. Asumiendo con humildad nuestros errores históricos y la disposición de superarlos, poder contribuir, de hecho, para la producción social de la resistencia a los mecanismos de control que, cada vez más, estarán sobre nuestras cabezas.

Pero el problema es: ¿queremos oponer resistencia? ¿No estamos, los educadores en general, embarcando muy fácilmente en los discursos macropolíticos, en los mecanismos de la educación mayor, que alardean a todos los vientos los tiempos de la evaluación

23 Ibídem, p. 218. 
permanente y de la formación continua? ¿No hemos sido, nosotros mismos, los vectores de la consolidación de las sociedades de control en el ámbito de la educación? Son cuestiones que se nos plantean para hacer proliferar el pensamiento, y no para paralizarlo.

\section{Enseñanza de filosofía en las sociedades de control}

Llegamos entonces al punto final de esta intervención: las condiciones para la enseñanza de la filosofía en las sociedades de control. ¿Cuál es el papel de la filosofía en este contexto? ¿Cuáles son sus sentidos?

Pienso que es posible afirmar que la filosofía presenta al menos dos facetas frente al poder: puede ser instrumento de legitimación y de mantenimiento del statu quo, pero también puede ser un instrumento de la resistencia, del enfrentamiento, de la transformación. Las dos facetas son encontradas en los diferentes momentos de la historia de la filosofía y también están presentes entre nosotros. Tenemos las filosofías de la legitimación de las sociedades de control, pero también tenemos las filosofías críticas a esta realidad, como aquella producida por Deleuze, por ejemplo.

Y también en el caso de la enseñanza de la filosofía se pone esta cuestión. Tomando como ejemplo el caso de Brasil, en los últimos diez años hemos discutido intensamente la inclusión obligatoria de la filosofía en los currículos de la educación media, realidad que se consolidó en este año de 2008, con la aprobación de un proyecto substitutivo de la Ley de Directrices y Bases de la Educación Nacional. Si luchamos por esta aprobación, no podemos dejar de estar atentos al hecho de que los intereses del Estado son aquellos dirigidos para la filosofía como un elemento de construcción, consolidación y mantenimiento de la ciudadanía. Y si vivimos en una sociedad de control, el ciudadano deseado es el ciudadano controlado. En el ámbito de una educación mayor, por lo tanto, lo que se espera de la filosofía es el ejercicio de su poder de legitimación social. Pero también podemos, en el ámbito de una educación menor, producir focos de resistencia ${ }^{24}$.

De modo general, experimentamos enseñar filosofía de manera escolástica, esto es, buscando transmitir, de forma organizada y metódica, un cierto corpus de conocimientos construidos a lo largo de la historia. En el ámbito de una didáctica de la filosofía, nos preocupamos entonces por la transmisibilidad de estos conocimientos, cómo transponerlos de modo que sean asimilables por los estudiantes. En este registro, estamos más preocupados con el enseñar que con el aprender, una vez que se toma como premisa que lo que es aprendido es aquello que es enseñado. Por otro lado, es común también que el profesor enseñe filosofía a partir de una "imagen de pensamiento" (de acuerdo con Deleuze, 2006), esto es, él enseña a partir de una determinada concepción de filosofía y de pensamiento que moviliza y define su propia forma de pensar, así como la forma de

\footnotetext{
${ }^{24}$ Deleuze en. "a Educação" (la Educación), trabajó con la idea de que la "educación mayor" es aquella producida en el ámbito de las políticas y planeamientos de la educación, en el nivel de los ministerios y secretarías de educación, en el nivel de las direcciones y coordinaciones de escuelas. Es una educación de la planificación, del planeamiento, de la proyección. Y "educación menor" es aquella que cada profesor efectivamente produce en la soledad de su salón de clase, soledad poblada por los alumnos allí presentes. Es una educación del posible, del efectivo, del acontecimiento.
} 
pensar que inducirá en los estudiantes. Enseñando en el ámbito de una imagen dada de pensamiento, el profesor ya definió de antemano lo que significa pensar y qué y cómo debe ser pensado por los estudiantes. Lo que la enseñanza de la filosofía moviliza en el estudiante, en este caso, es una especie de "reconocimiento", esto es, el estudiante es llevado a pensar lo ya pensado.

Jacques Rancière denominó "explicador" al maestro de este tipo de enseñanza, en la medida en que se centra en el proceso de explicar al discípulo una verdad. Y él está presente desde nuestros orígenes, desde los orígenes de la enseñanza de la filosofía. Es precisamente de ésto que trata la alegoría de la caverna: el filósofo que hace el transcurso del aprendizaje, libertándose de la contemplación de las sombras, tiene una especie de "deber moral" de retornar a la caverna y enseñar a sus iguales el camino de la verdad. La cuestión es que hoy vivimos en una especie de "sociedad pedagogizada", para usar la expresión de Rancière, que se produjo por el ejercicio de la máquina explicadora. Una sociedad así es embrutecedora, pues ligar el aprendizaje a la explicación pone la figura del maestro como central e imprescindible.

Pero hay al menos una disciplina en que esta lógica es (o puede ser) puesta en cuestión, por su propia naturaleza: la filosofía; este saber abierto por excelencia, que apuesta más al problema que a la solución. La lógica de la explicación, que parte de una solución ya dada, es, entonces, antifilosófica. Por esto, la presencia de la filosofía en la escuela puede ser un foco para desestabilizar esta pedagogización explicadora:

...la filosofía puede ser, en la institución, ese lugar donde se revierta el fundamento de la autoridad del saber, donde el sentimiento justo de la ignorancia aparezca como la verdadera superioridad del maestro: el maestro no es aquel que sabe y transmite; es aquel que aprende y hace aprender, aquel que, para hablar el lenguaje de los tiempos humanistas, hace su estudio y determina cada uno a hacer por su cuenta. La filosofía puede ocupar este punto de reversión porque ella es el lugar de una verdadera ignorancia. Todos saben que, desde el comienzo de la filosofía, los filósofos no saben nada, no por falta de estudio o de experiencias, sino por falta de identificación. También la enseñanza de la filosofía puede ser ese lugar donde la transmisión de los conocimientos se autoriza a pasar a algo más serio: la transmisión del sentimiento de ignorancia ${ }^{25}$.

Si la filosofía es el sentimiento de la ignorancia, es porque en ella es fundamental la experiencia del problema. No se produce filosofía sin un problema, lo que nos lleva a afirmar que el problema es el motor de la experiencia de pensamiento filosófico. Esta constatación llevó a González Porta ${ }^{26}$ a afirmar que "el no considerar el problema degrada la enseñanza o el estudio filosófico a un contar o escuchar historias”. Y nos hace

${ }^{25}$ RANCIÈRE Jacques. « Nous que sommes si critiques... ». En: VVAA: La Grève des Philosophes école et philosophie. Paris: Éditions Osiris, 1986, pp. 119-120.

${ }^{26}$ GONZALEZ PORTA, Mario Ariel. A filosofia a partir de seus problemas (La filosofía a partir de sus problemas). São Paulo: Ed. Loyola, 2002, p. 29. 
cuestionar: ¿qué pretendemos, al enseñar la filosofía?, ¿qué pretendemos que los estudiantes aprendan, al estudiar filosofía?

Si esperamos de la filosofía una especie de enseñanza activa, movilizada para que el estudiante sea capaz de pensar por sí mismo (esto es, un aprendizaje activo), más allá de las experiencias en que su actividad no es más que un "reconocimiento", como se afirmó anteriormente, entonces es necesario que él haga la experiencia del concepto, la experiencia del pensamiento conceptual. Por tanto, el proceso educativo debe partir de la experiencia del problema como movilizador y motor del pensamiento, para que sea posible la creación conceptual. Este parece ser el único camino posible para que la enseñanza de la filosofía no sea un mero "contar historias" y su estudio un mero "escuchar historias".

En la conferencia proferida para cineastas en la FEMIS, en 17 de marzo de 1987, Deleuze enfrentó el problema del hecho de creación en el pensamiento, hablando de la creación en el cine y en las artes, de modo general, en la ciencia, en la filosofía. Tratando de la filosofía, anticipa la tesis central de la obra que publicaría algunos años más tarde, afirmando que la filosofía es una disciplina creadora. Acompañemos su argumentación:

Es simple: la filosofía también es una disciplina creadora, tan inventiva como cualquier otra disciplina, y ella consiste en crear o aun inventar conceptos. Y los conceptos no existen hechos, en una especie de cielo en que ellos esperan que un filósofo los agarre. Es necesario fabricar los conceptos. Ciertamente, no se los fabrica así, de la nada. ¡No se dice, un día, "bien, voy inventar tal concepto”, como un pintor no dice, un día, "bien, voy a hacer un cuadro asî", o un cineasta "bien, voy a hacer tal película"! Es necesario que se tenga una necesidad, en filosofía o en los otros casos, sino no habría nada. Un creador no es un padre que trabaja por el placer. Un creador no hace nada más que aquello que absolutamente necesita. Resta que esta necesidad -que es una cosa bastante compleja, si ella existe- haga con que un filósofo (aquí, por lo menos yo sé de que él se ocupa) se proponga a inventar, a crear los conceptos y no a ocuparse de reflexionar, aún que sea sobre el cinema ${ }^{27}$.

Esta necesidad de la cual habla Deleuze, que mueve el hecho de creación, es, al menos en el caso de la filosofía, el problema. El problema es aquella incomodidad que perturba al filósofo, que no le permite descansar, que lo hace aventurarse en el pensamiento y fabricar los conceptos. En ¿Qué es la filosofía?, él afirmó que "no se crean conceptos, a no ser en función de los problemas que se consideran mal vistos o mal colocados" 28 , siendo eso lo que lleva a una "pedagogía del concepto": es preciso saber colocar bien el problema, para que el concepto pueda ser creado. Un problema desplazado, tomado del plano de inmanencia de otro filósofo y colocado en otro campo problemático, es un nuevo problema, es un problema propio, apto para dar oportunidad a nuevos conceptos.

${ }^{27}$ DELEUZE. G. Deux Régimes de Fous (Textes et entretiens, 1975-1995). Paris: Les Éditions de Minuit, 2003, p. 292.

${ }^{28}$ DELEUZE. Conversações, Op. cit., 1992, p. 28. 
Lo esencial, afirman Deleuze y Guattari, es que "todo concepto remite a un problema, a problemas sin los cuales no tendría sentido, y que sólo pueden ser aislados o comprendidos en la medida de su solución" ${ }^{29}$. Eso significa que la tarea de una "pedagogía del concepto" sería la de buscar hacer el movimiento inverso al de la creación, que parte del problema. Tomando un concepto dado, es necesario preguntar qué género de solución es y a qué tipo de problema o conjunto de problemas responde. El problema, que, como vimos, es sensible, prerracional, sólo puede ser comprendido, esto es, "ecuacionado" racionalmente, de forma regresiva, partiendo de su solución, que es el concepto. Así, diríamos que en el estudio de la filosofía no se trataría de comprender el concepto por el problema que lo suscita, sino, al contrario, comprender el problema a partir del conocimiento del concepto originado en él.

Podemos, por lo tanto, hacer un interesante estudio "escolar" de la filosofía a través de una pedagogía del concepto que, de algún modo, se asemejaría a una "pedagogía del problema", que consiste en proponer falsos problemas, impidiendo que se piense en el ámbito de una imagen dogmática del pensamiento. Una pedagogía del concepto, al contrario de la dogmática, tendría el mérito de develarnos los misterios de la creación de un concepto, misterios siempre singulares, concernientes a aquel concepto específico. Para cada concepto, un campo problemático, un conjunto de problemas, un conjunto de misterios involucrados en su creación. Por un "método regresivo" de la pedagogía del concepto, podríamos descubrir esos misterios, lo que, sin embargo, no nos autorizaría a colocar un método para creación de los conceptos, una vez que no hay métodos para la creación. Si Deleuze afirmó que "no hay método para encontrar tesoros ni para aprender",30, podemos agregar que no hay métodos para crear. Cada creador necesita inventar su propio método, su propio estilo creativo.

Proceder contra-inductivamente, afirmaba el epistemólogo Paul Feyerabend en Contra el Método, al procurar develar los caminos de la producción del conocimiento en la ciencia. No hay método puesto de antemano, sino la invención de caminos a partir de los problemas enfrentados. Si hablamos de método, hablamos a posteriori; sólo es posible identificar el camino de la invención, de la creación, después de que fue recorrido. Empirismo radical y absoluto, sin aprioris e innatismos, cuyo único punto de partida posible es el problema tomado como experiencia sensible ${ }^{31}$.

Una pedagogía del concepto, para la cual no hay método posible, so pena de caer en el reconocimiento, en la imagen dogmática, en la no creación, estaría entonces basada en esta doble actividad: experimentar el problema, producir el concepto, no siendo posible una sino por la otra, y sus modos de acción siendo siempre singulares, múltiples, plurales.

1992, pp. 27-28.

${ }^{30}$ Deleuze. Diferencia y Repetición. 2. a ed. Rio de Janeiro: Graal, 2006, p. 237.

${ }^{31}$ También Rajchman indica la pista de una posible relación del empirismo de Deleuze con Feyerabend, cuando apunta que "parecería entonces que hay afinidades entre la obra de Deleuze y el 'empirismo' de Feyerabend, con su proliferación en la ciencia de programas no unificados e inconmensurables" (2004, p. 24-25). 
Deleuze y Guattari afirmaron ${ }^{32}$ que ensañar es proferir, a través del lenguaje, palabras de orden, una vez que el lenguaje está hecho para obedecer y hacer obedecer. Si partimos de esta constatación, entonces la enseñanza de la filosofía no podría colocarse de otra manera, sino a través de la imposición de una imagen dogmática de pensamiento, de la instigación a un reconocimiento, de una cárcel al pensamiento como representación. Pero, valiéndome de las tesis de Rancière en O Mestre Ignorante (El Maestro Ignorante), pienso que es posible afirmar que esta constatación de Deleuze y Guattari arriba expuesta es válida en el contexto de la sociedad pedagogizada. Si es posible ofrecer resistencia a la sociedad pedagogizada, a la enseñanza embrutecedora, a través de un enseñanza emancipadora, en la posibilidad de construcción de una igualdad de hecho entre aquel que enseña y aquel que aprende, más allá de la asimetría pedagógica, entonces será posible invertir en un enseñanza de la filosofía que le apueste a un aprendizaje activo, en un enseñanza que implique un aprendizaje creativo y no simplemente reproductivo.

Para tal programa, la pedagogía del concepto se presenta como un camino viable, si tenemos en consideración lo que fue expuesto anteriormente, según lo cual, no se trata de un método de enseñanza, una vez que no hay métodos para aprender. Y para una pedagogía del concepto, la experiencia del problema tiene una importancia fundamental. Una enseñanza de la filosofía basada en la pedagogía del concepto significaría una mayor inversión en la problematización, esto es, en el planteamiento de los problemas, que en las soluciones. No es que el producto del pensamiento (el concepto) no sea importante, sino que su producción solo será posible a través de la vivencia del problema, y es importante que la producción del concepto no sea conclusiva, sino instigadora de nuevos problemas.

Pensar la enseñanza de la filosofía como el "cálculo diferencial del problema"; develar los problemas regresivamente, a partir de los conceptos, de modo que permita la experiencia del problema y la creación del concepto; dar la oportunidad así, a cada uno, de la experimentación del pensamiento en el registro de la filosofía. Y, como el aprendizaje es caracterizado por Deleuze como los "hechos subjetivos operados frente al problema", podemos inferir que el aprendizaje del problema, como experiencia del problema, puede redundar en la creación del concepto.

Si el aprendiz de natación es aquel que enfrenta el problema de nadar, nadando, el aprendiz de filosofía es aquel que enfrenta el problema del concepto pensando conceptualmente. No hay otro modo de aprender el movimiento del concepto que lanzándose al concepto. Y como no se puede aprender el concepto sino por el problema que lo incita, el aprendiz de filosofía necesita adentrarse en los campos problemáticos, necesita experimentar sensiblemente los problemas, de modo que pueda ver engendrado el hecho de pensar en su propio pensamiento.

Y como esta experiencia es necesariamente singular, como singulares son los componentes del concepto y del problema, el hecho de pensar ahí engendrado no redunda

32 Deleuze y Guattari. "20 de noviembre de 1923 - Postulados da Lingüística" (Postulados de la Lingüística). In: Mil Platôs - vol. 2. Rio de Janeiro: Ed. 34, 1995, pp. 11-12. 
en una repetición del mismo, en un reconocimiento, una vez que no se trata de una imagen dogmática del pensamiento, sino de un pensamiento sin imagen, virgen, genital.

Tomar el aprendizaje de la filosofía regresivamente, partiendo de los conceptos, para poder comprender los problemas que los suscitaron, moviliza en el aprendiz de filosofía la experimentación de los problemas como experiencia sensible. Y cuando esto efectivamente pasa, está abierto el camino para el pensamiento propio, instigado por la experiencia del problema.

\section{Finalizando... a modo de conclusión}

Cuando leemos los análisis alrededor de las sociedades de control, parece que estamos ante la realización de aquello que, a mediados del siglo veinte, George Orwell vislumbró en su romance 1984. Una vigilancia constante, como si viviésemos en un inmenso panóptico; cables invisibles controlando nuestros pensamientos y nuestras acciones. Uno de los aspectos más interesantes del romance de Orwell es justamente el control ejercido por el pensamiento, a través de la reducción y del empobrecimiento del lenguaje. Cada semana, el Estado publicaba una nueva edición del Diccionario de Novilingua cada vez menor, más enjuto. Cuanto menor era el repertorio lingüístico, menores eran las posibilidades de pensamiento y de creación. Pero hay siempre la posibilidad de resistir, de trazar líneas de fuga, por más arriesgadas y dolorosas que puedan ser.

Para nosotros, que nos dedicamos a enseñar filosofía, estos son los caminos abiertos: actuar como marionetas, movidos por los cables invisibles (a veces ni tan invisibles...) del control, enseñando en el modelo del reconocimiento, que no invierte en el pensamiento propio del estudiante, sino refuerza la repetición, el hecho de pensar lo mismo, lo ya pensado; o ser vectores de resistencia, invirtiendo en el desarrollo del pensamiento propio, invirtiendo en la emancipación de cada estudiante, trazando líneas de fuga con relación a los mecanismos de control. En el ámbito de una educación menor, en la soledad de nuestros salones de clase, cavamos nuestras trincheras y resistimos. Para esto es necesario, como afirmó Deleuze, creer en el mundo; creer que es posible resistir y crear. Ahí está lo que nos desafía.

\section{BIBLIOGRAFIA}

Boutang, Pierre-André. L’Abécédaire de Gilles Deleuze (3 DVD). Paris: Les Éditions Montparnasse, 2004.

Costa, Rogério da. "Sociedade de Controle". In: Cruz, Jorge (org.): Gilles Deleuze sentidos y expresiones. Rio de Janeiro: Ed. Ciência Moderna, 2006.

Deleuze, Gilles. Diferencia y Repetición. 2. ${ }^{a}$ ed., Rio de Janeiro: Graal, 2006.

. Deux Régimes de Fous (Textes et entretiens 1975-1995). Paris: Les Éditions de Minuit, 2003.

. Conversações (Conversaciones). Rio de Janeiro: Ed. 34, 1992. 
Francis Bacon - Lógica da Sensação (Lógica de la Sensación). Rio de Janeiro: Jorge Zahar, 2007.

Deleuze, Gilles; Guattari, Félix. O que é a filosofia?(¿Qué es la filosofía?) Rio de Janeiro: Ed. 34, 1992.

. "20 de noviembre de 1923 - Postulados da Lingüística" (Postulados de la Linguiística). In: Mil Platôs - vol. 2. Rio de Janeiro: Ed. 34, 1995.

DeleuZE, Gilles; Parnet, Claire. Diálogos. São Paulo: Escuta (Escucha), 1998.

Feyerabend, Paul. Contra o Método (Contra el Método). 3. a ed., Rio de Janeiro: Francisco Alves, 1989.

Foucault, Michel. Resumen de los Cursos del Collège de France (1970-1982). Rio de Janeiro: Jorge Zahar, 1997.

. Em Defesa da Sociedade (En Defensa de la Sociedad). São Paulo: Martins Fontes, 1999.

. Segurança, Território, População (Seguridad, Territorio, Población). São Paulo: Martins Fontes, 2008.

Gallo, Sílvio. Deleuze \& la Educación. 2. ${ }^{\mathrm{a}}$ ed., Belo Horizonte: Ed. Autêntica, 2008.

GIL, José. "O Alfabeto do Pensamento" (El Alfabeto del Pensamiento) (Prefacio a la edición portuguesa de Diferencia y Repetición). In: Deleuze, Gilles. Diferencia y Repetición. Lisboa: Relógio D’Água, 2000, pp. 9-29.

GONZÁlez PortA, Mario Ariel. A filosofia a partir de seus problemas (La filosofía a partir de sus problemas). São Paulo: Ed. Loyola, 2002.

HARDT, Michael. "A Sociedade Mundial de Controle" (La Sociedad Mundial de Control). In: Alliez, E. (org.): Gilles Deleuze: una vida filosófica. São Paulo: Ed. 34, 2000.

NEGRI, Antonio; HARDT, Michael. Império (Imperio). Rio de Janeiro: Record, 2001.

Rajchman, John. Deleuze un mapa. Buenos Aires: Ed. Nueva Visión, 2004.

RANCIÈRE, Jacques. «Nous que sommes si critiques...». In : VVAA: La Grève des Philosophes - école et philosophie. Paris: Éditions Osiris, 1986.

. O Mestre Ignorante (El Maestro Ignorante). Belo Horizonte: Autêntica, 2002. 